\title{
Creative Thinking Based on Mathematical Reasoning Ability in Solving Geometry Problems in High School
}

\author{
Ainun Rahma Firdausy ${ }^{1 *}$ Triyanto $^{2}$ Diari Indriati $^{3}$ \\ ${ }^{1}$ Postgraduate School of Mathematics Education, Faculty of Teacher Training and Education, Universitas \\ Sebelas Maret, Indonesia \\ ${ }^{2}$ Faculty of Teacher Training and Education, Universitas Sebelas Maret, Indonesia \\ ${ }^{3}$ Department of Mathematics, Faculty of Mathematics and Natural Sciences, Universitas Sebelas Maret, \\ Indonesia \\ * Corresponding author. Email: inunrahma29@gmail.com
}

\begin{abstract}
This study aims to describe mathematical creative thinking based on categories of mathematical reasoning at high, moderate, and low levels, in geometry problems. This research is a qualitative descriptive study. The test was given to 30 twelfth graders at SMA Negeri 4 Surakarta. Based on the results, students are classified into students with high, medium and low reasoning abilities. Five subjects were selected by purposive sampling technique to analyze their creative thinking skills. The research instruments were tests and interviews. The aspects of creative thinking that were measured were fluency, flexibility and originality. Based on the results of the analysis, it was concluded that most students with high reasoning abilities were able to fulfill two aspects of creative thinking skills, students with moderate reasoning abilities only met one aspect of creative thinking skills and students with low reasoning abilities could not fulfill any aspect of creative thinking abilities. Students with high reasoning abilities could provide answers in different ways easily and were able to provide two different solving strategies. Students in the medium and low reasoning categories were only able to answer questions, but have not been able to fulfill all aspects of creative thinking well.
\end{abstract}

Keywords: Authenticity, Creative, Flexibility, Fluency, Geometry, Mathematical.

\section{INTRODUCTION}

In the $21^{\text {st }}$ century, mathematics is considered as one of the most important subjects. The purpose of mathematics education is to produce students who have skills in solving problems and foster high interest and motivation in mathematics [1]. The main focus of education today is no longer about teaching reading, writing, and arithmetic. Judging from the results of the mathematics test based on the 2018 Program for International Student Assessment (PISA), Indonesia obtained a score of 379 on mathematical literacy. This score is far below the international average, which is 489. Moreover, the average score for the national mathematics exam at the high school level is 39.33 (IPA), 34.46 (IPS) and 37.60 (Language). This shows that there are problems in learning mathematics at school.
Senior High School 4 Surakarta is one of the favorite schools in Surakarta City, yet students' ability to absorb mathematics is still below $50 \%$. This is quite worrying, considering that Senior High School 4 Surakarta is a leading school. The students' ability to understand geometry and trigonometry was the lowest, which nationally only reached $21.56 \%$ (social studies major) and $34.59 \%$ (science major). This is certainly a highlight in education, especially for schools, considering the large role of geometry and trigonometry both in the scope of mathematics and its role in training problem-solving skills in other fields, for example, science, engineering, economics, and others.

Mathematics learning in schools that still tend to consistently use the lecture method causes students to lack understanding of basic mathematical concepts. Students struggle to understand mathematics because 
mathematics is something abstract, while students are accustomed to thinking concretely [1]. So far, students' learning patterns are only memorizing and mechanistic [2]. One of the things that is suspected to be the cause of the inactivity of students in mathematics discussions, especially in the geometry chapter, is due to the lack of students' abilities in creative thinking and reasoning, so students have difficulty giving ideas to solve problems. The factor for the low reasoning ability of students is because the tasks given by the teacher tend to only emphasize understanding concepts, while the teacher rarely gives tasks that require students to think at a higher level, including mathematical reasoning [3]. Whereas the results of the study say that creative thinking skills if encouraged properly, can improve mathematical achievement [4].

Based on the analysis of PISA results (2018), it is known that to be successful in the PISA test, students must be able to reason mathematically and be able to use concepts, procedures, facts, and tools in mathematics to describe, explain, and predict phenomena. Mathematical reasoning is the process of inferring the solution of a problem from a given problem [5]. Mathematical reasoning plays an important role in students' thinking skills, both in solving problems and in conveying ideas when learning mathematics [6]. Mathematical reasoning can be improved, one of which is through practicing creative thinking skills [7].

In addition, the basic skills required by students based on the P21 Framework 21st Century Learning include critical thinking, communication, collaboration, and creativity. The ability to think creatively is one of the indicators of the skills tested in PISA [8] and abilities that students must possess [9]. Creative thinking skills are abilities that can help students to find various ideas or problem solving solutions, not only problems in mathematics but also in life [10]. This shows that mathematical reasoning and creative thinking skills are very important for students to have [11].

Indicators of mathematical reasoning in this study include the ability to draw conclusions, perform mathematical manipulations, provide valid arguments, and present mathematical statements [12]. Students with a high level of reasoning ability are students who meet the criteria for either all or at least three indicators of reasoning ability. Students with moderate mathematical reasoning abilities are students who are only able to meet two of the four indicators of reasoning ability, and the minimum criteria is moderate. Students with low mathematical reasoning ability are students who only meet one or none of the four indicators of mathematical reasoning ability. The difficulties experienced by students in achieving high criteria in mathematical reasoning abilities are caused by the lack of students in the ability to analyze, generalize, integrate, give reasons, and solve nonroutine problems [3].

Previous research said that most students were able to master the indicators of mathematical manipulation and present mathematical statements orally, in writing, or in pictures. However, most students are not good at indicators of drawing conclusions from a statement and providing valid arguments [12]. This shows that to solve a mathematical problem that requires logical reasoning, students need the ability to think creatively. Student creativity in mathematics is generally related to problem solving or problem posing [13]. Creative thinking skills will help students express mathematical ideas to solve a problem in a unique way.

The correlation between creative thinking and mathematical reasoning can be seen based on the criteria of mathematical reasoning which include memorized reasoning, algorithmic reasoning, and creative reasoning. [14]. This shows that creative thinking and mathematical reasoning abilities influence each other. There are four characteristics of creative reasoning, which include novelty, flexibility, logic, and a strong mathematical basis [15]. described several aspects of creativity which include fluency, flexibility, originality, and elaboration [16]. Characteristics of creative reasoning by [15] shows the similarity of aspects of creative thinking with the theory developed by [16], this indicates that to achieve good creative thinking skills, students also need to master mathematical reasoning skills.

Previous research studies revealed that there is a positive relationship between creative thinking and students' academic performance. The average correlation between creative thinking and student academic achievement is 0.22 [17]. Meanwhile, another study revealed that to be able to assess creativity through writing tasks and scientific reasoning tasks [18]. There are studies that divide creative thinking skills into 2 , which include divergent thinking and convergent thinking. In divergent thinking, students are able to produce many answers to questions that do not have standard solutions [19]. In convergent thinking, students are able to determine how steps are needed when identifying a problem [20].

Based on this description, the researcher wants to describe students' creative thinking skills in terms of mathematical reasoning in solving geometry problems. 


\section{METHOD}

This research used descriptive qualitative method. Descriptive qualitative is a type of research that produces descriptive data in the form of a description of students' creative thinking skills based on mathematical reasoning in solving geometry problems. There are two types of instruments used in this study, the main instrument (researcher) and supporting instruments (tests and interviews). The test was given to 30 students of class XII SMA Negeri 4 Surakarta. Based on the results of the students' reasoning test answers, students were classified into students with high, medium, and low reasoning abilities. Based on these classifications, the most unique answers from each category were selected for further analysis. Five subjects were selected by purposive sampling technique to then be tested for creative thinking skills and interviewed. The results of the tests and interviews are then compared to determine the validity of the data.

The first step to categorize students' reasoning abilities is by doing a reasoning ability test consisting of four questions, each based on an indicator of mathematical reasoning. The creative thinking skills test consisted of 3 questions, each question representing one aspect of mathematical reasoning. The questions given have passed the validation process by experts and were stated as questions that can be used to measure the mathematical creative thinking skills of high school students based on mathematical reasoning.

Students are classified into students with high, medium and low mathematical reasoning abilities. Students are said to have high mathematical reasoning when students are able to meet all available reasoning indicators or at least three indicators are met. Medium mathematical reasoning students are students who are only able to fulfill two of the four indicators. Low mathematical reasoning students are students who are only able to fulfill one indicator or none of the four indicators. The distribution of subjects from each level of mathematical reasoning ability is presented in Table 1, Table 2, and Table 3

Aspects of creative thinking skills are: 1) fluency aspect, 2) flexibility aspect, and 3) originality aspect. Fluency is a state in which a person is able to think fluently, so that it will be possible to get more ideas. Flexibility is a condition when students are able to write various problem-solving strategies in sequence and explain the process of solving them. Authenticity is a condition when students are able to write down
Table 1. Subject code students with high reasoning ability

\begin{tabular}{|c|l|}
\hline $\begin{array}{c}\text { Level Students with High } \\
\text { Reasoning Ability }\end{array}$ & \multicolumn{1}{|c|}{ Subject Code } \\
\hline $\mathrm{M}-17$ & $\mathrm{H}-1$ \\
\hline $\mathrm{M}-21$ & $\mathrm{H}-2$ \\
\hline $\mathrm{M}-10$ & $\mathrm{H}-3$ \\
\hline
\end{tabular}

Table 2. Subject code students with moderate reasoning ability

\begin{tabular}{|c|l|}
\hline $\begin{array}{c}\text { Level Students with Moderate } \\
\text { Reasoning Ability }\end{array}$ & Subject Code \\
\hline $\mathrm{M}-2$ & $\mathrm{M}-1$ \\
\hline $\mathrm{M}-16$ & $\mathrm{M}-2$ \\
\hline
\end{tabular}

Table 3. Subject code students with low reasoning ability

\begin{tabular}{|c|c|}
\hline $\begin{array}{c}\text { Level Students with Low } \\
\text { Reasoning Ability }\end{array}$ & Subject Code \\
\hline S-30 & L-1 \\
\hline
\end{tabular}

various possible answers/new strategies to solve mathematical problems.

\section{RESULT AND DISCUSSIONS}

The data obtained in this study is data on students' creative thinking skills in each aspect based on the level of mathematical reasoning. The test for creative thinking skills consisted of three questions, each question contains aspects that must be achieved by students. The following are the results of students' work with high, moderate, and low reasoning categories.

\subsection{Students with High Reasoning Ability}

Students with high mathematical reasoning ability are students who are able to fulfill all or at least three indicators of mathematical reasoning ability. The reasoning indicators in this study include drawing conclusions, performing mathematical manipulations, providing valid arguments, and presenting mathematical statements.

\subsubsection{Fluency}

Question number 1 was used to measure the ability to think creatively in the fluency aspect. Fluency is 
related to students' ability to write down various possible answers correctly and fluently without difficulty. In the fluency indicator, the answers are said to be diverse if the methods used are different, but under a certain pattern or have the same idea [21]. Figure 1, Figure 2, and Figure 3 show an overview of the answers from subject $\mathrm{H}-1$.

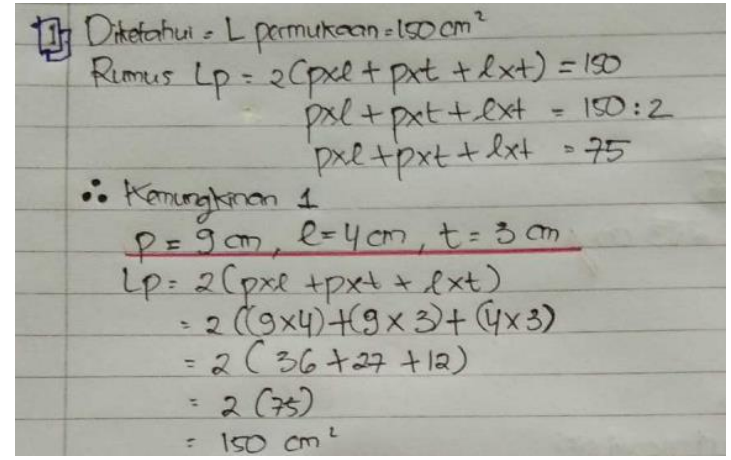

Figure 1 Answer from $\mathrm{H}-1$, for probability 1

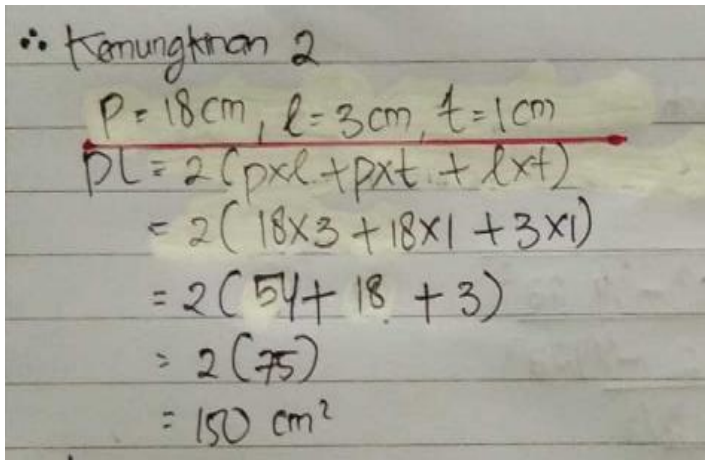

Figure 2 Answer from $\mathrm{H}-1$, for probability 2

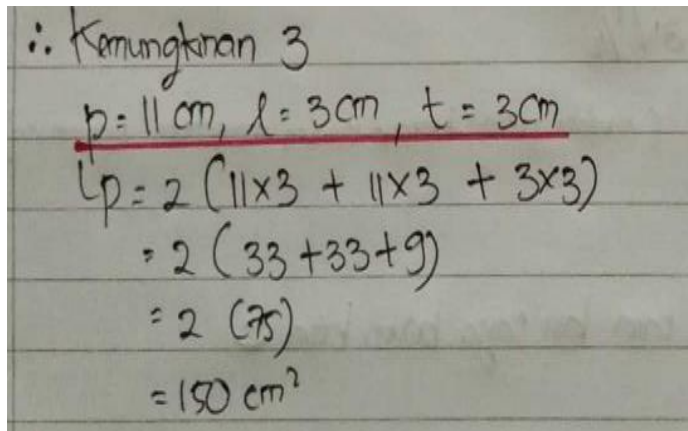

Figure 3 Answer from $\mathrm{H}-1$, for probability 3

In Figure 1, it is shown that the subject of $\mathrm{H}-1$ wrote down the completion steps systematically, starting with writing the known information, then writing the formula for the surface area of the block. In Figure 2 and Figure 3 it can be seen that $\mathrm{H}-1$ gave three different possible answers to find the size for the length, width, and height of a block. The results of the interview show that $\mathrm{H}-1$ is able to re-explain the steps for finding possible side sizes of the block in detail and easy to understand.

Subject H-2 can write down two possible answers regarding the length, width, and height of the block. However, H-2's answer has a slight difference compared to H-1's answer. Presented in Figure 4, although $\mathrm{H}-2$ provided two possible answers, the value written is actually only exchanged between the width and the height of the block.

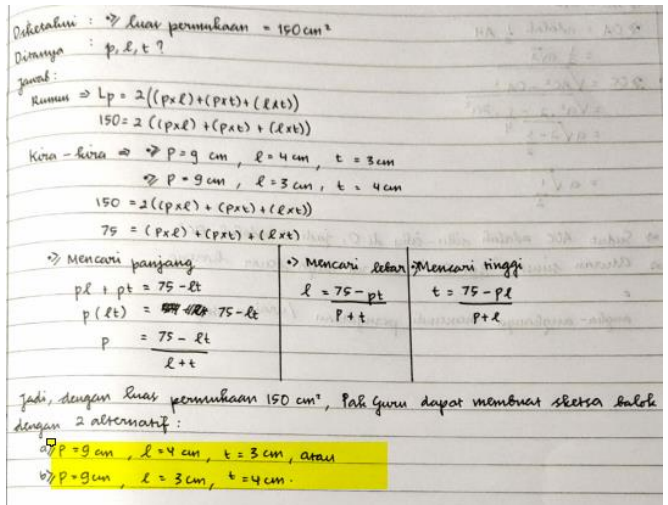

Figure 4 Answer from $\mathrm{H}-2$

The results of the interview showed that $\mathrm{H}-2$ could re-explain the steps to get the answer, even though it was only in the form of a brief explanation. H-2 mentioned that the first step is to describe the formula for the surface area of the block and describe the length, width, and height. Then $\mathrm{H}-2$ tried to match some numbers and gets two answers as shown on the answer sheet.

Subject H-3 gave a different answer from the answer of subject $\mathrm{H}-1$ and $\mathrm{H}-2$. Presented in Figure 5 and Figure 6, that $\mathrm{H}-3$ gives 2 possible answers for the length of the edges in each block. The difference in the answers between $\mathrm{H}-3$ and $\mathrm{H}-1$ and $\mathrm{H}-2$ lies in the type of number. The final answer $\mathrm{H}-3$ is a natural number (containing decimals and fractions), while it is clearly seen in the final answers $\mathrm{H}-1$ and $\mathrm{H}-2$ they answer with integers.

1. Ukuran yang dapat memenuhi syarat

$$
\text { a) } \begin{aligned}
150 & =2(p \cdot l)+2(p \cdot t)+2 \cdot(l \cdot t) \\
150 & =2(6 \cdot 6)+2(6 \cdot x)+2 \cdot(6 \cdot x) \\
150 & =72+12 x+12 x \\
150 & =72+24 x \\
-24 x & =-78 \\
x & =\frac{-78}{-24} \\
x & =3,25 \mathrm{~cm} \\
\text { Jadi } p & =6 ; l=6 ; t=3,25
\end{aligned}
$$

Figure 5 Answer from $\mathrm{H}-3$, for probability 1 


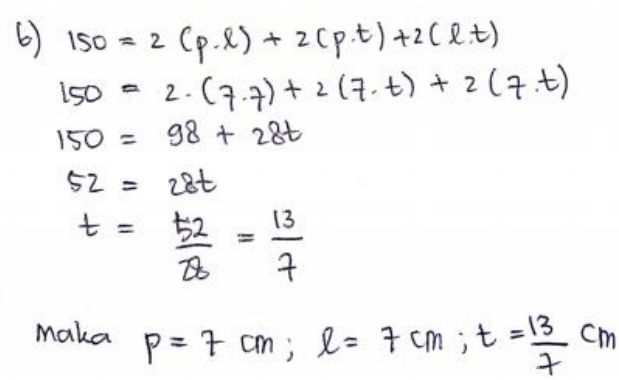

Figure 6 Answer from $\mathrm{H}-3$, for probability 2

\subsubsection{Flexibility}

Question number 2 was used to measure the ability to think creatively in terms of flexibility. The flexibility aspect is related to how students are able to solve problems with different strategies and how students are able to explain the problem-solving process. The settlement strategy is said to be different if the answers given look different and do not follow the same pattern/idea [21]. Subject $\mathrm{H}-1$ answers are presented in Figure 7 and Figure 8.

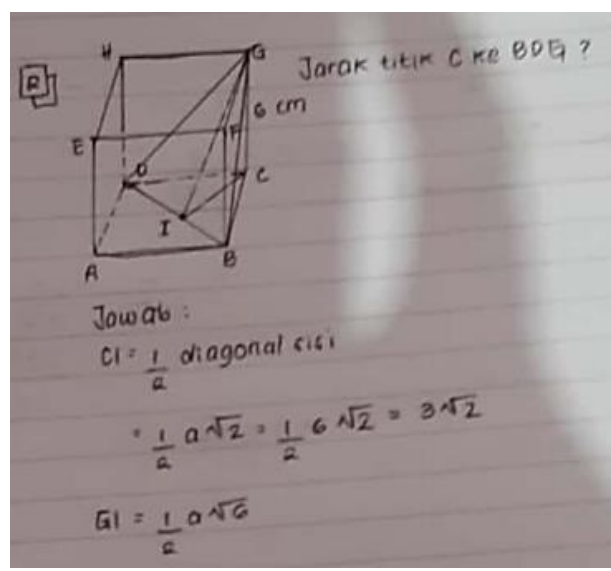

Figure 7 Answer from $\mathrm{H}-1$, first strategy

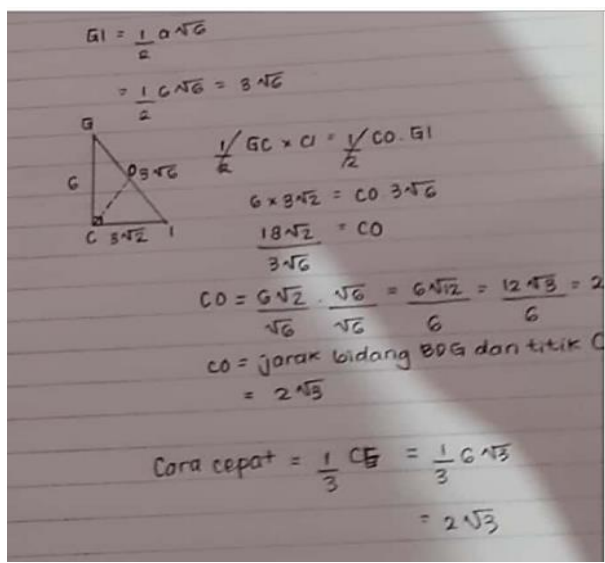

Figure 8 Answer from $\mathrm{H}-1$, second strategy
In Figure 7 it can be seen that $\mathrm{H}-1$ obtains the distance of a point on a plane by first sketching the cube. $\mathrm{H}-1$ does the completion steps in a coherent and clear manner. In Figure 8 it is shown that $\mathrm{H}-1$ is able to write more than one solution strategy, the first way is by using the concept of a triangle area comparison and the second way is by using a quick formula. Both methods produce the correct answer which is $2 \sqrt{ } 3 \mathrm{~cm}$.

Based on the answer sheet $\mathrm{T}-1$, it appears that $\mathrm{T}-1$ uses spatial sketches in solving it, this is in accordance with the findings which show that higher-level reasoning is characterized by evidence of visualization skills of how to solve a problem and is proficient in communicating goals [22]. On the interview, $\mathrm{H}-1$ said that the strategy he chose was the result of his memory and had been worked on before. The results of the interview also showed that $\mathrm{H}-1$ was able to re-explain the completion steps quite well and clearly.

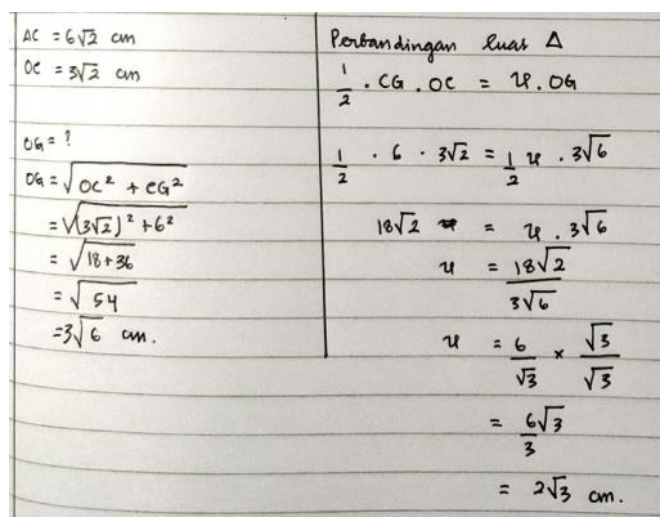

Figure 9 Answer from $\mathrm{H}-2$ about Flexibility

Subject H-2 was able to write two solutions strategy to find the distance from a point to the plane. In Figure 9 it is shown when H-2 uses the concept of the ratio of the area of a triangle. The results of the interview with the subject of $\mathrm{H}-2$ revealed that $\mathrm{H}-2$ could re-explain the completion steps even though $\mathrm{H}$ 2 had a little difficulty in describing it. The two strategies by $\mathrm{H}-2$ have similar and precise answers.

Subject H-3 wrote the completion steps to calculate the distance from point $\mathrm{C}$ to the BDG plane as shown in Figure 10. However, the answer given by $\mathrm{H}-3$ was not correct because $\mathrm{H}-3$ was not careful when calculating the distance from point $\mathrm{C}$ to point $\mathrm{O}$. point $\mathrm{O}$ is calculated with the concept of a side diagonal which is $6 \sqrt{ } 2 \mathrm{~cm}$ instead of $6 \sqrt{ } 3 \mathrm{~cm}$. The results of the interview show that $\mathrm{H}-3$ is still not able to understand the questions. Even H-3 still can't tell the difference between the side diagonal and the space diagonal. H-3 gave incomplete answers and stuck with quick formulas. 


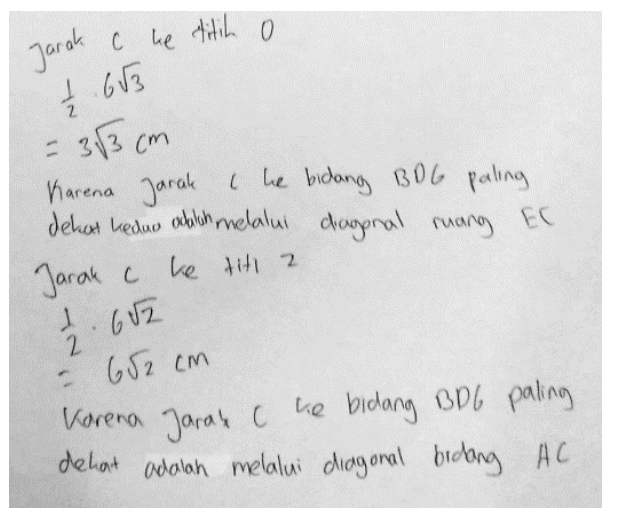

Figure 10 Answer from H-3

Based on the results of written answers and interviews with $\mathrm{H}-3$, it was found that $\mathrm{H}-3$ did not master the flexibility aspect, this aspect includes the ability to write various problem-solving strategies and provide valid arguments related to certain strategies.

\subsubsection{Originality}

Question number 3 is used to measure creative thinking in the aspect of originality. The aspect of originality is related to the ability to think original which means that students must be able to come up with new ideas that are not common. The criteria in this study are students are expected to be able to provide answers that are only used by less than $10 \%$ of students in the class, so these answers can be categorized as new answers. The following is a snippet of the answer to the subject of $\mathrm{H}-1$, which is presented in Figure 11.

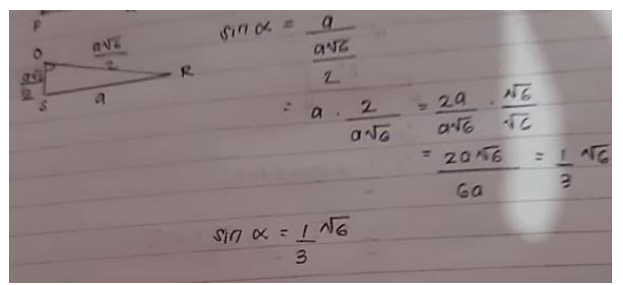

Figure 11 Answer Originality from $\mathrm{H}-1$

Figure 11 shows the answers of subject H-1. H-1 solves the problem by directly providing a different solution strategy from the example answer. The solution strategy written by $\mathrm{H}-1$ is by using the $\sin \alpha$ formula. Based on the results of written answers and interviews with $\mathrm{H}-1, \mathrm{H}-1$ has not mastered the originality aspect because the strategy chosen by $\mathrm{H}-1$ is also used by many other subjects. Originality can be assessed from the infrequent use of the strategy, for example, the strategy is used by less than $10 \%$ of students in the class, then the strategy can be categorized as an original strategy.

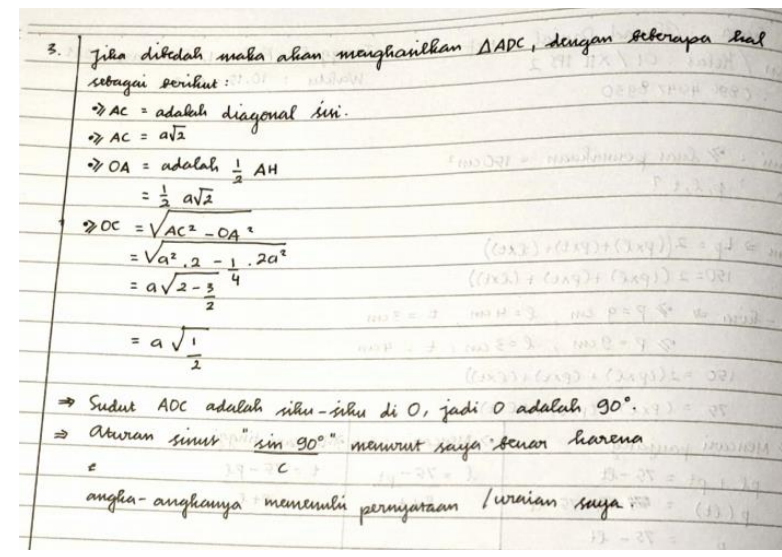

Figure 12 Answer Originality from $\mathrm{H}-2$

Based on Figure 12, it can be seen that $\mathrm{H}-2$ solved the problem by proving that the example answer to the question is correct but $\mathrm{H}-2$ does not provide another strategy. The results of the interview show that $\mathrm{H}-2$ has not been able to understand the questions correctly. $\mathrm{H}$ 2 does not read the instructions on the problem carefully. But H-2 can explain the answer he wrote clearly and coherently. $\mathrm{H}-2$ can also provide arguments regarding the steps to prove the strategy exemplified in the problem. Based on the results of written answers and interviews with $\mathrm{H}-2, \mathrm{H}-2$ has not been able to meet the originality aspect.

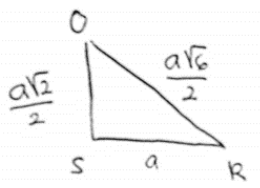

$$
\begin{aligned}
\cos \alpha & =\frac{s a}{m i} \\
& =\frac{\frac{a \sqrt{2}}{2}}{\frac{a \sqrt{6}}{2}} \\
& =\frac{a \sqrt{2}}{2} \cdot \frac{2}{a \sqrt{6}} \\
& =\frac{a \sqrt{2} \cdot 2}{2 \cdot a \sqrt{6}} \\
& =\frac{\sqrt{2}}{\sqrt{6}} \cdot \frac{\sqrt{6}}{\sqrt{6}}=\frac{112}{6} \\
\cos & \alpha \frac{1}{6} \sqrt{12} \\
\alpha & =\cos ^{-1}\left(\frac{1}{6} \sqrt{12}\right)
\end{aligned}
$$

Figure 13 Answer Originality from $\mathrm{H}-3$

Figure 13 shows the results of H-3's answer. The solution strategy chosen by $\mathrm{H}-3$ is the $\cos \alpha$ formula. The results of the interview show that $\mathrm{H}-3$ understands the problem and can explain how to calculate the angle $\alpha$ by using the cos formula correctly. H-3 finds the angle by dividing the length of the side OS (opposite) by the length of the side OR (the hypotenuse). H-3 obtains the length of each side by using the concept of the Pythagorean formula. Based on the results of written answers and interviews with $\mathrm{H}-3, \mathrm{H}-3$ has met the originality aspect because the strategy chosen by 
H-3 is used by less than $10 \%$ of students in the class, so the strategy can be categorized as an original strategy.

The three subjects with high mathematical reasoning abilities were able to fulfill two of the three aspects of mathematical creative thinking skills. However, only one subject is able to meet the originality aspect of mathematical creative thinking skills. Mastering two of the three aspects requires more complex thinking activities and a better understanding of geometric concepts. This is in line with previous research which revealed that there was a significant relationship between creative thinking and student achievement [23].

\subsection{Students with Moderate Reasoning Ability}

Students with moderate mathematical reasoning abilities are students who are only able to fulfill two of the four indicators, these four indicators are 1) drawing conclusions, 2) performing mathematical manipulations, 3) providing valid arguments, and 4) being able to present mathematical statements.

\subsubsection{Fluency}

The answer given by the subject M-1 is presented in Figure 14. In Figure 14, it can be seen that M-1 only provides two pictures of spatial figures along with their measurements, M-1 does not write down the detailed completion steps.

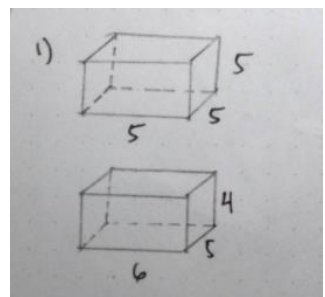

Figure 14 Answer Fluency from M-1

The results of the interview show that M-1 is able to find the length of each side of a block, but unfortunately, M-1 still doesn't understand the difference between the concept of a block and a cube. Because with the size written by $\mathrm{M}-1$, then the first figure is a cube, this is not in accordance with the command in the question. Besides, the size in the second figure is not correct, the final result does not show the value of $150 \mathrm{~cm}^{2}$. Based on the results of written answers and interviews with $\mathrm{M}-1$, it is known that M-1 has not mastered the fluency aspect.

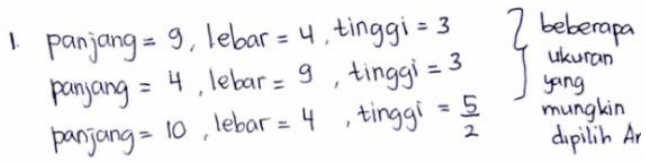

Figure 15 Answer Fluency from M-2

In Figure 15, the answer to the subject of M-2 is presented. M-2 wrote three possible lengths of each edge on the block, but M-2 did not write down the steps for solving it systematically and in detail. M-2 only writes the final answer without any steps and does not write down the information that is known from the question. The results of the interview showed that $\mathrm{M}$ 2 could answer/explain the answer but it took longer than other subjects.

It can be seen in Figure 15 that the second possible answer is only the first possible answer whose numbers are swapped (length becomes wide, width becomes long, height remains high). M-2 operates numbers accurately and thoroughly so that all the final answers obtained are correct. Based on the results of written answers and interviews with $\mathrm{M}-2$, it is known that M-2 meets the fluency aspect.

\subsubsection{Flexibility}

The results of M-1's written answers are presented in Figure 16. It can be seen in Figure 16 that M-1 writes down two completion steps related to calculating the distance from point $\mathrm{C}$ to $\mathrm{BDG}$. The first method uses the ratio of the area of the triangle and the second method uses the space diagonal formula. M-1 described the completion steps in sequence and detail.

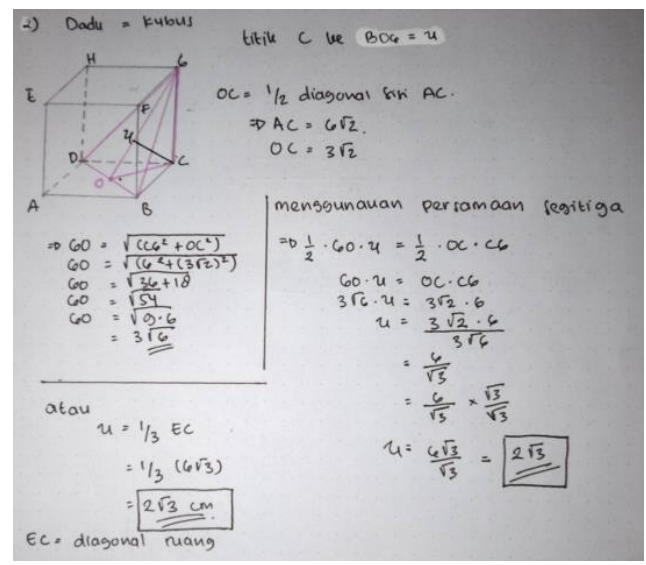

Figure 16 Answer Flexibility from M-1

The results of the interview show that M-1 can understand the questions. Even Subject M-1 is able to provide two different ways with the right end result. M-1 can also explain the steps of completion in a 
systematic, complete, and clear manner. This is supported by the results of the study, which revealed that tasks that require students to perform non-routine procedures require students to identify and result in students being able to be more creative [24]. Based on the results of written answers and interviews with M1 , it was found that M-1 had fulfilled the flexibility aspect.

Subject M-2 wrote a completion step related to calculating the distance presented in Figure 17. However, the steps written by M-2 did not reach the required final answer. The sketch written by $\mathrm{M}-2$ along with the steps has only reached $1 / 3$ of the whole step.

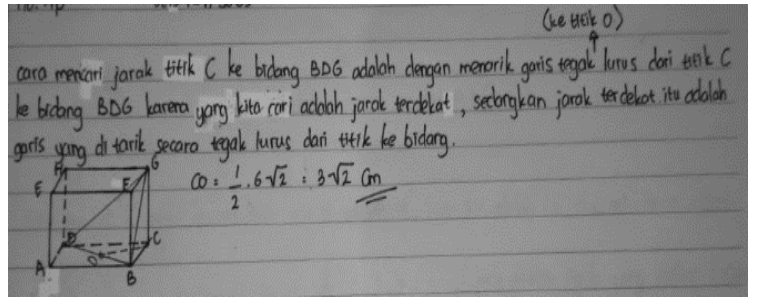

Figure 17 Answer Flexibility from M-2

The results of the interview showed that the subject of M-2 was not able to answer completely. M-2 cannot even determine which line can be used to calculate the distance from point $\mathrm{C}$ to BDG. M-2 does not master the flexibility aspect in the indicators of writing various problem-solving strategies or providing valid arguments related to the chosen solution strategy.

\subsubsection{Originality}

Question number 3 measures students' creative thinking skills in the aspect of originality. The answer to the subject of M-1 is presented in Figure 18. The solution strategy chosen by $\mathrm{M}-1$ is $\cos \alpha$ formula. However, M-1 did not answer the question carefully, M-1 substituted the value so that the final answer was not correct.

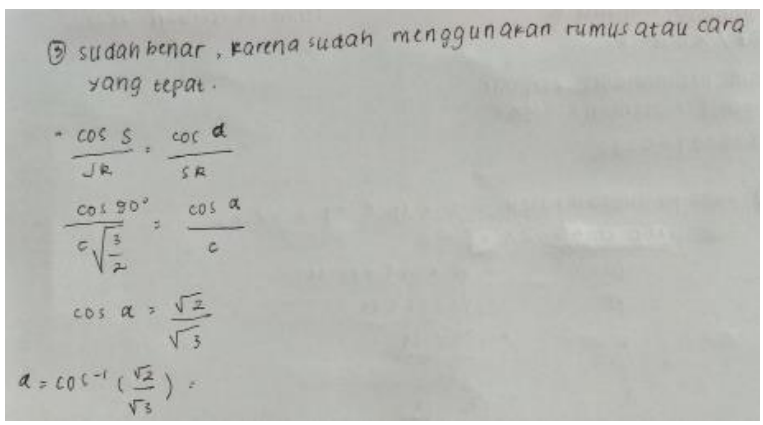

Figure 18 Answer Originality from M-1
The results of the interview show that M-1 has not been able to understand the problem, especially understanding the concept of trigonometric formulas. It can be seen in Figure 18 that M-1 only replaces the formula but does not change the value. It is clearly seen that M-1 only memorizing the formula but does not understand the concept. Based on the results of written answers and interviews with M-1, M-1 has not been able to meet the originality aspect because the final answer obtained is incorrect.

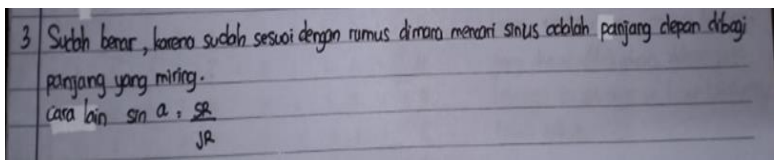

Figure 19 Answer Originality from M-2

The results of the answers of the subjects M-2 are presented in Figure 19. In Figure 19 it can be seen that the solution strategy chosen by M-2 is by using $\sin \alpha$ formula. However, M-2 does not give the exact number, M-2 only writes the formula without writing the final answer for the angle size of $\alpha$.

The results of the interview show that M-2 only knows the formula sin, but cannot apply it to the problem. Actually, M-2 can find solutions other than the answers that have been exemplified in the problem. M-2 only memorized the formula without completing the final answer. Based on the results of written answers and interviews with M-2, M-2 does not meet the originality aspect because the final answer given by M-2 is not correct. The difficulty of students in solving geometry problems is influenced by several factors, including because students lack experience in solving problems and lack understanding [25].

The two subjects with moderate mathematical reasoning abilities only met one of the three aspects of mathematical creative thinking skills. M-1 only mastered the flexibility aspect, while M-2 only mastered the fluency aspect. There are no subjects who master the originality aspect of mathematical creative thinking skills. On average the subjects gave general answers. The reason is that the subject failed to understand the instructions on the question so that the information provided in the question did not help the subject solve the problem [10].

\subsection{Students with Low Reasoning Ability}

Students with moderate mathematical reasoning abilities are students who are only able to meet one of the four indicators, these four indicators are 1) drawing conclusions, 2) performing mathematical manipulations, 3) providing valid arguments, and 4) being able to present mathematical statements. 


\subsubsection{Fluency} 20.

The answer by subject L-1 is presented in Figure

Subject L-1 wrote down the completion steps in detail and coherently to find the length, width, and height of the beam. However, L-1 only wrote one possible answer.

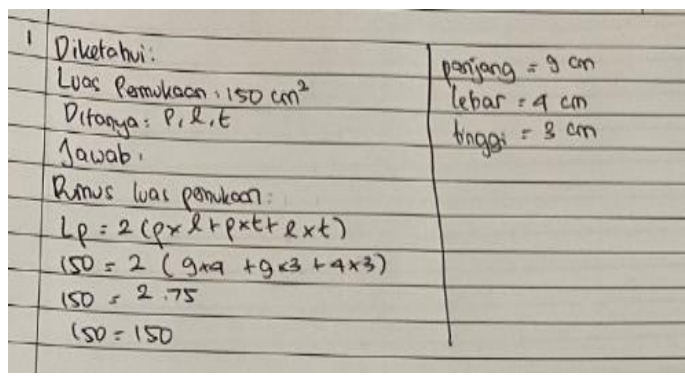

Figure 20 Answer Fluency from L-1

The results of the interview with L-1 show that L1 can find the side length of the block even though he only gets one possible answer. It can be seen that L-1 can re-explain the solution steps, but it turns out that L-1 is not sure about the steps/strategy he chose. L-1 said it took him longer to find the length, width, and height of the block. L-1 is able to find several possible answers correctly if he knew the clue. Based on the results of written answers and interviews with L-1, it was found that L-1 had not been able to fulfill the fluency aspect.

\subsubsection{Flexibility}

The result of the written answer by L-1 is presented in Figure 21.

\begin{tabular}{|c|c|c|}
\hline \multirow[t]{2}{*}{2} & $A C=6 \sqrt{2} \mathrm{~cm}$ & Perbandingan loas a \\
\hline & $O C=3 \sqrt{2}$ or & $1 / 2 C 6 \times O C=u . O C$ \\
\hline & & $1 / 2 \cdot 6 \cdot 3 \sqrt{2} \cdot 1 / 2 u \cdot 3 \sqrt{6}$ \\
\hline & $O G=\sqrt{x^{2}+C 6^{2}}$ & $18 \sqrt{2}=u 3 \sqrt{6}$ \\
\hline & $=\sqrt{\left(3 \sqrt{21^{2}+6^{2}}\right.}$ & $u=18 \sqrt{2}$ \\
\hline & $=\sqrt{18+\% 6}$ & $3 \sqrt{6}$ \\
\hline & $=\sqrt{59}$ & $u=\frac{6}{\sqrt{3}} \times \sqrt{3}$ \\
\hline & $=3 \sqrt{6} \mathrm{~cm}$ & $\sqrt{3} \sqrt{3}$ \\
\hline & & $=\frac{6}{3} \sqrt{3}$ \\
\hline & & 3 \\
\hline & & $=2 \sqrt{3} \mathrm{~cm}$ \\
\hline
\end{tabular}

Figure 21 Answer Flexibility from L-1

Subject L-1 wrote a solution related to calculating the distance by using the ratio of the area of a triangle. However, L-1 only writes 1 solution step. The completion steps written by L-1 are also detailed and systematic.
The results of the interviews showed that L-1 was able to understand the questions and solve problems on the questions.

The results of the interview showed that L-1 was able to understand and complete what was developed in the questions. However, R-1 seems like it is difficult to explain the steps of the process. This is in accordance with research which reveals that students' level of reasoning can be seen from how students build mathematical ideas and communicate them via language [26].

However, L-1 only provided one solution strategy using the ratio of the area of the triangle. L-1 solved with a ratio of the area of the triangle because he had previously encountered a similar problem, so he found it difficult to find other strategies.

Based on the results of written answers and interviews with L-1, it was found that L- 1 was able to complete the calculation of the point-to-plane distance but only by using 1 strategy. So L-1 is not able to fulfill the flexibility aspect, both indicators write various problem solving strategies and provide valid arguments related to the chosen solution strategy.

\subsubsection{Originality}

The result of the written answer by L-1 is presented in Figure 22.

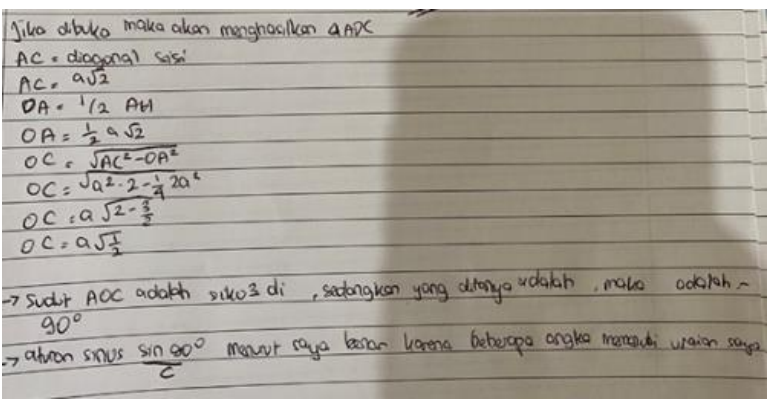

Figure 22 Answer Originality from L-1

Based on Figure 22, it can be seen that L-1 provides an argument related to an example of a solution. However, L-1 does not provide other alternative solutions. The proof given by L-1 is also inaccurate because it appears that the arguments given are still convoluted.

The results of the interview showed that L-1 did not understand what was asked in the question. After further investigation, it turned out that L-1 only knew $\sin \alpha$ and $\cos \alpha$ formulas, but could not apply those formulas to the problem. Even though L-1 can calculate it, he still needs more detailed instructions. Based on the results of written answers and interviews 
with L-1, L-1 has not been able to fulfill the originality aspect because the final answer given by L-1 is incorrect.

In the subject with a low level of mathematical reasoning, the subject does not meet any aspect of the mathematical creative thinking ability. Subject can only provide answers but cannot achieve the fulfillment of aspects of creative thinking skills. This is in line with the argument from previous research which revealed that someone with low reasoning ability will always have difficulty in dealing with various problems because they are unable to connect the facts to draw a conclusion [25]. Students only remember or memorize a concept (recall). The reasoning is a thinking activity that has a level far above remembering. The levels of thinking in reasoning are basic thinking, critical thinking, and creative thinking [27].

\section{CONCLUSION}

Based on the results of the analysis, it was concluded that most students with high reasoning abilities were able to fulfill two aspects of creative thinking skills, students with moderate reasoning abilities only met one aspect of creative thinking skills, and students with low reasoning abilities could not fulfill any aspect of creative thinking abilities.

Students with high reasoning abilities can easily meet the fluency and flexibility aspects, which are able to provide answers to various problems and are able to provide two different solving strategies. This is because students with high reasoning tend to be more detailed and coherent in solving problems. Students with high reasoning are also better able to solve more varied questions than students with moderate and low reasoning. However, high reasoning students face difficulties in being able to meet the authenticity aspect. On average, students are only able to answer the problem in the usual way, a method that is also used by $10 \%$ of other students' answers. Students in the medium and low reasoning categories were only able to answer questions, but have not been able to fulfill all aspects of creative thinking well.

\section{ACKNOWLEDGMENTS}

The researcher would like to thank SMAN 4 Surakarta for their help and cooperation so that researchers can complete the data related to the Creative Thinking Ability of Students Based on mathematical reasoning in solving geometry problems in senior high school.

\section{REFERENCES}

[1] N. Riastuti, M. Mardiyana, and I. Pramudya, "Students' Errors in Geometry Viewed from Spatial Intelligence," J. Phys. Conf. Ser., vol. 895 , no. 1, 2017, doi: 10.1088/1742$6596 / 895 / 1 / 012029$.

[2] Ç. Biber, A. Tuna, and S. Korkmaz, "The Mistakes and the Misconceptions of the Eighth Grade Students on the Subject of Angles.," vol. 1, no. 2, pp. 50-59, 2013.

[3] A. Rizta, Z. Zulkardi, and Y. Hartono, "Pengembangan Soal Penalaran Model TIMSS Matematika SMP," J. Penelit. dan Eval. Pendidik., vol. 17, no. 2, pp. 230-240, 2013, doi: 10.21831/pep.v17i2.1697.

[4] S. M. Jacob, "Mathematical Achievement and Critical Thinking Skills in Asynchronous Discussion Forums," Procedia - Soc. Behav. Sci., vol. 31, no. 2011, pp. 800-804, 2012, doi: 10.1016/j.sbspro.2011.12.144.

[5] W. Hidayat, Wahyudin, and S. Prabawanto, 'Improving Students' Creative Mathematical Reasoning Ability Students through Adversity Quotient and Argument Driven Inquiry Learning," J. Phys. Conf. Ser., vol. 948, no. 1, 2018, doi: 10.1088/1742-6596/948/1/012005.

[6] C. S. Ayal, Y. S. Kusuma, J. Sabandar, and J. A. Dahlan, "The Enhancement of Mathematical Reasoning Ability of Junior High School Students by Applying Mind Mapping Strategy'.," J. Educ. Pract., vol. 7, no. 25, pp. 50-58, 2016.

[7] A. N. Chukwuyenum, "Impact of Critical Thinking on Performance in Mathematics among Senior Secondary School Students in Lagos State," IOSR J. Res. Method Educ., vol. 3 , no. 5, pp. 18-25, 2013, doi: 10.9790/73880351825 .

[8] I. Pratiwi, "Efek Program PISA terhadap Kurikulum di Indonesia," J. Pendidik. dan Kebud., vol. 4, no. 1, p. 51, 2019, doi: 10.24832/jpnk.v4i1.1157.

[9] OECD, "The Future of Education and Skills: Education 2030," 2018. [Online]. Available: http://www.oecd.org/education/2030/E2030 Position Paper (05.04.2018).pdf.

[10] S. I. Kulsum, T. T. Wijaya, W. Hidayat, and J. Kumala, "Analysis on High School Students' Mathematical Creative Thinking Skills on The Topic of Sets," J. Cendekia J. Pendidik. Mat., 
vol. 3, no. 2, pp. 431-436, 2019, doi: 10.31004/cendekia.v3i2.128.

[11] R. Lince, "Creative Thinking Ability to Increase Student Mathematical of Junior High School by Applying Models Numbered Heads Together," J. Educ. Pract., vol. 7, no. 6, pp. 206-212, 2016.

[12] A. R. Firdausy, Triyanto, and D. Indriati, "Mathematical Reasoning Abilities of High School Students in Solving Contextual Problems," Int. J. Sci. Soc., vol. 3, no. 1, pp. 201-211, 2021.

[13] M. Nadjafikhah, N. Yaftian, and S. Bakhshalizadeh, "Mathematical creativity: Some Definitions and Characteristics," Procedia-Soc. Behav. Sci., vol. 31, no. 2011, pp. 285-291, 2012, doi: 10.1016/j.sbspro.2011.12.056.

[14] Sukirwan, D. Darhim, and T. Herman, "Analysis of Students' Mathematical Reasoning," J. Phys. Conf. Ser., vol. 948, no. 1, 2018, doi: 10.1088/17426596/948/1/012036.

[15] J. Lithner, "A Research Framework for Creative and Imitative Reasoning," Educ. Stud. Math., vol. 67, no. 3, pp. 255-276, 2008, doi: 10.1007/s10649-007-9104-2.

[16] B. Sriraman, "Are Giftedness and Creativity," Math. Teach., vol. XVII, no. 1, pp. 20-36, 2005.

[17] A. Gajda, M. Karwowski, and R. A. Beghetto, "Journal of Educational Psychology Creativity and Academic Achievement: A Meta-Analysis Creativity and Academic Achievement: A Meta-Analysis," J. Educ. Psychol., vol. 109, no. 2, p. 269, 2016.

[18] R. J. Sternberg, "Creating a Vision of Creativity: The First 25 Years.," Psychol. Aesthetics, Creat. Arts, vol. S, no. 1, pp. 2-12, 2006, doi: 10.1037/1931-3896.s.1.2.

[19] E. Volle, “Associative and controlled cognition in divergent thinking: Theoretical, experimental, neuroimaging evidence, and new directions," Cambridge Handb. Neurosci. Creat., no. 1, pp. 333-360, 2018, doi: 10.1017/9781316556238.020.

[20] U. Sternberg and W. Prieß, "Extremely Fast Calculation of 13C Chemical Shift Tensors Using the Bond Polarization Theory," ACS Symp. Ser., vol. 732, pp. 93-100, 1999, doi:

\subsection{1/bk-1999-0732.ch006.}

[21] B. Ardiyanto, M. Abdulloh, S. Septiasari, L. Setyaningrum, P. Matematika, and U. Tidar, "Analisis Kemampuan Berpikir Kreatif Matematis Siswa Kelas XI SMA Islam Secang pada Materi Trigonometri,” pp. 59-64, 2019.

[22] R. Seah and M. Horne, "Developing reasoning within a geometric learning progression: Implications for curriculum development and classroom practices," Aust. J. Educ., 2021, doi: 10.1177/00049441211036532.

[23] M. . Anwar, Muhammad Aness, Asma Khizar, Muhammad Naseer, and Gulam Muhammad, "Relationship of Creative Thinking with The Academic Achievements of Secondary School Students," Int. Interdiscip. J. Educ., vol. 1, no. 3, pp. 1-4, 2012.

[24] M. K. Stein and J. H. Kaufman, "Selecting and supporting the use of Mathematics curricula at scale," Am. Educ. Res. J., vol. 47, no. 3, pp. 663-693, 2010, doi: $10.3102 / 0002831209361210$.

[25] Y. Junaedi, Wahyudin, and D. Juandi, "Mathematical Creative Thinking Ability of Junior High School Students' on Polyhedron," J. Phys. Conf. Ser., vol. 1806, no. 1, 2021, doi: 10.1088/1742-6596/1806/1/012069.

[26] L. C. Wilkinson, A. L. Bailey, and C. A. Maher, "Students' Mathematical Reasoning, Communication, and Language Representations: A Video-Narrative Analysis," ECNU Rev. Educ., vol. 1, no. 3, pp. 1-22, 2018, doi: 10.30926/ecnuroe2018010301.

[27] M. S. Zuhri, T. A. K, and I. Sujadi, "Karakteristik Penalaran Siswa Kelas XI Sekolah Menengah Atas tentang Sampel," pp. 24-33, 2004. 